\title{
Teaching team construction of Circuits Theory under the background of the pilot college
}

\author{
Shiwei Su \\ College of Electrical Engineering \&New Energy \\ China Three Gorges University \\ Yichang, china \\ 21864436@qq.com
}

\begin{abstract}
In view of the different pilot class training mode and goal, student-centered, with course construction as the core, build a teaching team of circuits Theory. Study on the team cooperation mechanism, Combined with construction of teaching material, the design of teaching content and teaching method reform, teaching staff construction,etc. Construct a teaching team which has a high standard of teaching, knowledge structure matching reasonable, realize knowledge sharing, promote the exchange of teaching research and teaching experience, so as to promote the pilot institute reforms and improve the quality of personnel training.
\end{abstract}

Keywords-pilot college; curricula construction; the teaching team; circuits theory

\section{INTRODUCTION}

Circuits Theory is an important technology basic course of electrical major; it was in a core position of the electrical major courses. Figure 1 is the course setting of electrical engineering and automation, circuit's theory plays an essential role in the major curriculum system. Aim at a system of three cultivation model that Integrate comprehensive development and personality development, explore the construction of a high teaching quality, reasonable structure of circuits theory teaching team. Through the establishment of the teaching team cooperation mechanism, reform the teaching contents and

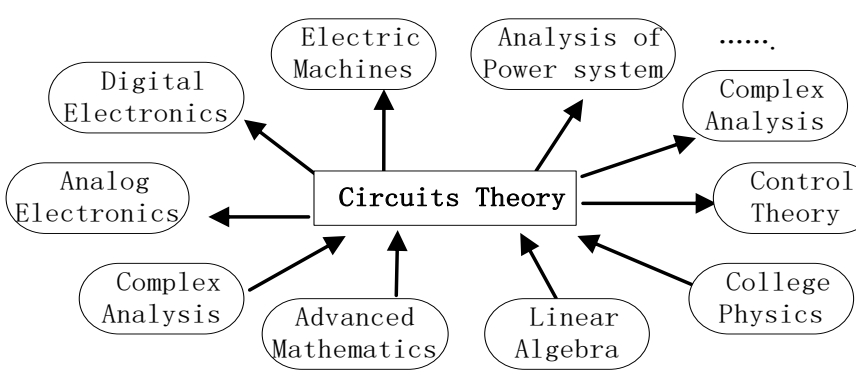

Fig. 1.Circuits theory in the core position in the electrical major courses

methods, development of teaching resources, promote the exchange of teaching and the teaching experience, promote the teaching of impart, assistance and bring together, improve teachers' teaching level, make it play a positive and effective in teaching work and teaching reform, so as to improve the quality of personnel training.

\author{
Wei Xiong \\ College of Electrical Engineering \&New Energy \\ China Three Gorges University \\ Yichang, china \\ 7424601@qq.com
}

\section{THE CONSTRUCTION OF TEACHING TEAM}

The construction of teaching team in colleges and universities is to carry out scientific development view of higher education, important content to improve the quality of teaching, it is an important part in the process of the education teaching reform. [1]As a link to teaching, the common goal is to improve the teaching quality of circuits theory education, collaboration, Complementary knowledge and skills, ,combine the goal of cultivate "Electrical talent", "excellent engineers"[2], “internationalization", Integration of excellent resources, The teaching team building model of circuits theory as shown in figure 2. Under the quality engineering team goals, Composition echelon structure.

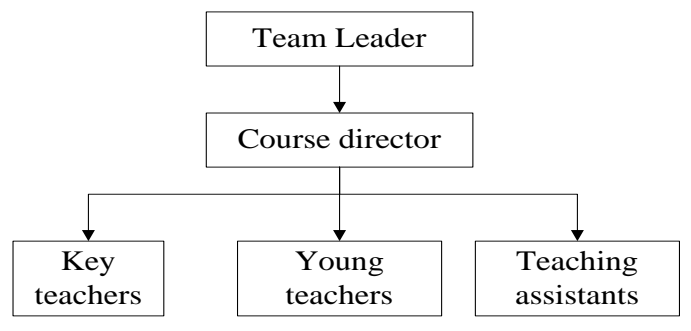

Fig. 2.Circuit course teaching team building model

\section{THE OPERATION MECHANISM OF TEACHING TEAM}

Under the mode of the teaching team, The leader of teaching team and Course director Develop the construction planning Supervise the implementation of various tasks, The key teachers are nucleus who gradually develop and grow up from Young teachers After many years of teaching practice, they are the connecting link between the preceding and the following.Young teachers are The most innovative group, Is the cultivation of the team, teaching assistant can effectively extend class[3]. Through the experiment and discussion, combine with the theory of teaching perfectly. Under the mode of the teaching team, be more conducive to teaching and researching activities organization. Under the guidance of team leader, In order to develop the course construction, teaching team mainly around the following aspects[4]: 


\section{A. Textbook construction}

Teaching material is embodied knowledge carrier of teaching contents and teaching methods, Reference on the construction of excellent teaching material at home and abroad, To build three-dimensional, diversified, series of teaching materials for the target, Based on the training objective of individual talents, Correctly grasp the teaching content and curriculum system reform direction, According to the training objectives of the pilot class and the syllabus requirements, formulate the plan and implementation plan of the special teaching material. Also it can choose excellent English teaching materials, bilingual teaching or the implementation of the whole English Teaching.

At present, the circuit of the experimental class in our college use the textbook which is Fundamentals of Electric Circuits (Fifth Edition),it is the mechanical industry press, Written by Charles K. Alexander; Matthew N. O. Sadiku, Bilingual Teaching.

\section{B. The design of teaching content}

At present, teachers are still based on the explaining; Practice link is lack of practical engineering background of the design and comprehensive experiments. From the point of view of students, the curriculum is dull and the circuit is complex and difficult to understand, and lack of intuitive knowledge, eager to do hands-on practice. In view of this, the group members through regular exchanges, discussion, selection of classic teaching content and deletion of obsolete content, remove the course between duplicate content, from the students learning ability, practical ability and innovative ability to consider, for different types of pilot classes together and formulating and revising the syllabus, teaching plans, lesson plans, test questions, test links and content. Explore the combination of curriculum development and research, practice teaching and scientific research.

Under the premise of ensuring the reasonable structure of knowledge, the theory teaching focuses on the simple circuit analysis method, avoiding too complex circuit analysis of examples. At the same time, an example to analyze, with a focus on selecting the actual life is close to the circuit. lean subsequent courses in the use of complex circuit analysis method, streamline the analysis of circuit model of mathematical and physical requirements are relatively high.

Strengthen the practice teaching; the research of the practice teaching can promote the theory teaching method, the training student's practical ability and the innovation ability. Circuit is a practical course, it is very difficult to make the students learn well, and teachers must let the students in practice to learn, deepen understanding. Cultivate students' ability to analyze problems and solve problems, to stimulate students' initiative and creativity. In the course of theory curriculum, the practice of curriculum, especially the theoretical course, can be used in the practical course of middle school students have or will be used in the content. At the same time, according to different students with different requirements, for the practical ability of students can also be will electronic innovation contest into to the students' practical teaching, to carry out students to design their own experimental competition mode.
Integrate theory and experimental courses, make the theory become the real theory; let the practice become fertile ground for the development of theory. It Research on the problems and solutions of the students' participation in extracurricular scientific and technological activities.

\section{Exploration and reform of teaching method}

The teaching of theory course mainly embodies the principle of heuristic teaching, which inspires students to study independently, take the initiative and independent thinking. The specific teaching methods are: heuristic teaching method, the teaching method of the problem, the "demonstration" teaching method, the extracurricular research, the design method, the interactive teaching method. The combination of modern teaching method with the traditional teaching method, the reasonable use of the multimedia technology, is to improve the teaching effect. The construction of the course website is "China Three Gorges University Exploration of school" etc.

Experimental basis on the cultivation of students' basic experimental skills and innovation consciousness, guided by "foundation experiment five steps", make solid foundation experimental skills and to enhance the ability which is professional practice ability and innovation ability.

In the operation mode of the teaching team, carry out the research on the teaching method of the research, and to form the teaching method of the different curriculum characteristic. And according to the different types of pilot classes, using different teaching methods, new knowledge and new technology into teaching content, pay attention to the integration between curriculum knowledge, curriculum, professional between penetration and between disciplines cross by all contributed to the cultivation of students' autonomous learning and inquiry ability of teaching methods, and fully mobilize the enthusiasm of the teachers and students to learn. The content of classroom teaching and after class assignments must be reached above 1:3. Regularly carry out academic exchange activities, encourage academic cross, concise academic direction; on the teaching methods and forms, is a combination of computer technology, network technology and modern teaching equipment, improve the students' ability of independent thinking and innovation ability.

\section{Evaluation of teaching effect}

Actively explore, dare to try new examination method, pay attention to the process of teaching, pay attention to the ability to test students' knowledge; work out a set of practical teaching quality evaluation system, to enable teachers to keep abreast of the teaching effect, the students to master, make teachers more focused to organize the teaching activities. Under the teaching team mechanism, the curriculum group organizes the teaching research activity and the lecture activity, the exchange experience, promotes the teaching level enhancement, enhances the teaching quality.

\section{TEACHING TEAM CONSTRUCTION OF TEACHERS}

China's future hopes in education, the key to education in the teacher. Teacher troop is the decisive factor of the quality 
of personnel training[5]. There is no high-quality teachers, can't cultivate high-quality personnel.

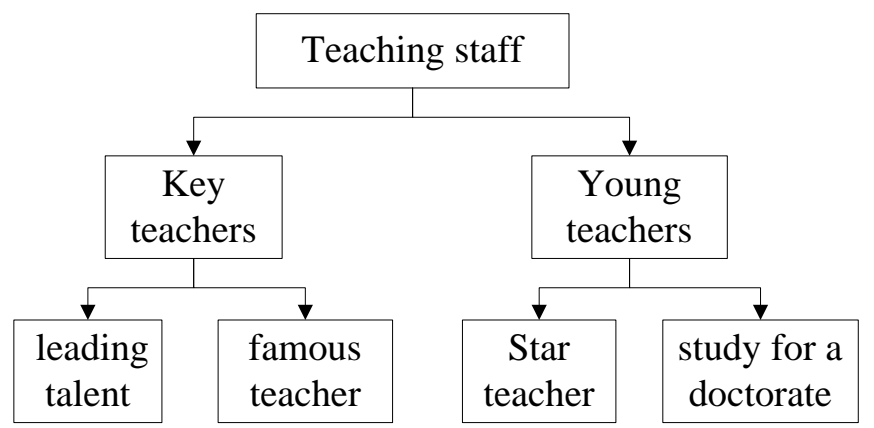

Fig. 3.The construction and training of the teaching staff of the curriculum group

The construction of teaching staff is the primary goal and the development of the teaching team. The building of the contingent of teachers is the key to improve the structure of teachers' comprehensive quality and to optimize the faculty, the electricity class specialized basic course teaching team of teachers team construction direction as shown in Figure 3. Among them, the backbone of the teaching grasp the direction of teaching reform and the task to implement, to leading talents, teachers teaching in the direction of the development of the reserve talents; young teachers through continuous training and re education is improved, to the direction of the development of the teaching research backbone reserve personnel. To strengthen the training of teachers training, training and the introduction of outstanding teachers and research team with international advanced level, the construction of teaching staff can be studied from the following aspects[6]:

\section{A. Education related structure}

In the introduction of talent it is not only emphasizes the learning edge structure, but also focus on the work experience of the enterprise. Also according to the characteristics of the curriculum group rational planning, formulation of teachers training scheme; employment in the field of domestic enterprises with certain specialty of people come to the school as a extracurricular guidance teachers, academic lectures, provide training base, scholarships etc.

\section{B. Teacher, rookie training}

In the process of the construction of teaching team to teacher training, to create high-quality curriculum as a goal, for every young teachers equipped with at least a mentor, play a role in the backbone, the words and deeds of the, to promote the rapid growth of young teachers; to comprehensive curriculum group organized in the form of basic course teaching, and give full play to the Teaching Committee of expert supervision in the supervision and guidance of the role of classroom teaching, by the steering group selection recommend and guide curriculum group of outstanding teachers in teaching competition, for the cultivation of teaching teachers, teaching rookie build demonstrate the capabilities of the platform; encourage or sending outstanding young teachers to domestic and foreign well-known colleges and universities to pursue a doctorate.

\section{To improve the system construction of teaching staff development}

Enhance the professional quality of the teachers' engineering ability, strengthen the engineering background. First, try efforts to introduction of engineering experience of teachers from enterprises and research institutes; Second, encourage teachers to participate in scientific research, through the cooperation of production, teaching and research, improve teachers' level of scientific research and engineering practice ability; Third, send young teachers into the enterprise practical learning, implementation of not less than one year of engineering practice ability training plan[7].

Strengthen the teaching quality evaluation, establish the quality of the teaching quality and academic level of the evaluation and reward performance mechanism. Including members of learning, selection, motivation, management, elimination and a series of system, we must continue to build and improve. Strengthen the diversification of teacher teaching means, especially how to combine scientific research, teaching and practice, and teachers can consciously the research way of thinking and the spirit of exploration into the basic course teaching, to cultivate students' innovation ability, practical ability and international perspective of top-notch innovative personnel.

\section{CONCLUSION}

To strengthen the construction of teaching team in the traction circuit training, a lively situation, thus making full use of the form give full scope to the talents, the establishment of a teaching team which have a cohesive and fighting capacity, teaching level and knowledge structure suitable matching, it can realize knowledge sharing, promote research and teaching experience of communication teaching and establish an effective cooperation mechanism between team members. Through the reform of teaching syllabus, teaching materials, the teaching methods and means, school enterprise cooperation to promote the pilot reform, improve the teaching quality and improve the quality of personnel training, for the pilot school reform of the accumulated experience, to achieve the demonstration and promotion.

\section{ACKNOWLEDGMENT}

This paper was sponsored by the research project of China Three Gorges University and contract NO: J2014014 and KJ2015013.

\section{REFERENCES}

[1] Wanyong Liang,yong Jiang,weifeng Cao. Research on the teaching of basic course of electric power oriented to "excellent plan" [J].Electric Power Education in China,2013,02:85-86.

[2] Dong Xie,min Wang.Research on the teaching of electronic technology course based on the "excellence program", Electric Power Education in China,2011,28:80-81+83.

[3] Zhonghua Chen,xiaohuan Yan,weihua Chen. On the construction of excellent teaching team in the basic course of Electrical EngineeringTake Liaoning Technical University as an example [J]. Chinese modern educational equipment,2012,01. 
[4] Chunrong Song,xiequan Liu,mengli Feng,yuping Cai. Strengthening the construction of the teaching team of the basic course of the personnel training $[\mathrm{J}]$. Chinese Education Innovation Herald,2012,NO.31.

[5] Wen Wang. On the construction of teachers in Local Engineering Colleges [J].Higher engineering education research,2012,06.

[6] Xianshan Li,Xiangyong Hu,Xuejun Zhou,Yunhai Zhou,Huijia Liu,Jianxiu Xiao.Electrical engineering and its automation specialty application oriented personnel training, The Sixth National College
Electrical Engineering and automation professional teaching reform seminar. 2009,08;106-110;

[7] Yongqi Tang,Shaoping Huang,Guofan Liu,Jianqiang Liu.School enterprise cooperation training "excellence engineer".- To implementthe "excellent engineer education and training plan" as an example in Hunan Institute of Engineering. Educational exploration. 2010.NO.12,71-74. 